\title{
Mitigating carnivore-livestock conflict in Europe: lessons from Slovakia
}

\author{
Robin Rigg, Slavomír Findo, Maria Wechselberger, Martyn L. Gorman, \\ Cla dio Sillero-Zubiri and David W. Macdonald
}

\begin{abstract}
Conflicts with human interests have reappeared following recovery of large carnivores in Europe. Public acceptance is higher than historically but there is a need to identify effective, acceptable techniques to facilitate coexistence. We present a case study of predation on livestock in Slovakia. Damage, mitigation measures and public opinion were assessed using compensation records, analysis of farm conditions, questionnaire surveys, semi-structured interviews, diet analysis and on-farm trials of livestock-guarding dogs. Economic damage was inconsequential on a national scale but high locally: c. $80 \%$ of reported losses occurred at $12 \%$ of sheep flocks. Grey wolves Canis lupus were held responsible for four to six times more damage than brown bears Ursus arctos, although livestock occurred in only 2 of 78 wolf faeces during spring-autumn, when sheep and cattle were most vulnerable. Losses to Eurasian lynx Lynx lynx were negligible. Compared to other sectors of society shepherds had the most negative attitudes, particularly towards wolves, despite compensation payments. Appropriate use of livestock-guarding dogs was associated with fewer losses: median loss at trial flocks with predation was $70 \%$ lower than at control flocks. We conclude that identifying vulnerable farms and targeting them for mitigation could reduce damage, although lack of motivation and awareness are obstacles. This study shows that damage levels need not be excessive despite high predator densities in humandominated landscapes. Conflicts were unevenly distributed, with much of the variation explained by local conditions and husbandry practices, especially preventive measures. Livestock-guarding dogs are particularly appropriate where wolves are present in proximity to unfenced pastures.
\end{abstract}

Keywords Brown bear, Canis lupus, damage prevention, grey wolf, livestock-guarding dogs, livestock predation, Lynx lynx, Ursus arctos

RoBIN RIGG (Corresponding author) Slovak Wildlife Society, P.O. Box 72, Liptovský Hrádok 033 01, Slovakia. E-mail info@slovakwildlife.org

SLAvomír FinĎo Carpathian Wildlife Society, Zvolen, Slovakia

Maria WechSelberger Slovak Wildlife Society, Liptovský Hrádok, Slovakia

Martyn L. Gorman Zoology Department, School of Biological Sciences, University of Aberdeen, Aberdeen, UK

Claudio Sillero-Zubiri and David W. Macdonald Wildlife Conservation Research Unit, The Recanati-Kaplan Centre, Zoology Department, University of Oxford, Tubney, UK

Received 16 July 2009. Revision requested 7 September 2009.

Accepted 8 December 2009.

\section{Introduction}

R ecovery of large carnivores in Europe has been accomR panied by a re-emergence of ancient conflicts with human interests (Kaczensky, 1996). Carnivores prey on livestock, damage crops, compete with hunters for game and occasionally injure or even kill humans (Woodroffe et al., 2005). Historically, people retaliated with persecution, precipitating declines in carnivore populations (Breitenmoser, 1998). Together with a better understanding of ecology, however, a change in society's attitudes has resulted in legal protection for many species of carnivore (Mech, 1996). Large carnivores can coexist with humans given favourable management policy (Linnell et al., 2001) but, to avoid a return to unsustainable levels of lethal control, there is a need to mitigate conflicts in ways that are both effective and acceptable (Sillero-Zubiri \& Laurenson, 2001).

Many non-lethal methods have been tried to reduce livestock predation, the most prevalent conflict (reviewed in Cluff \& Murray, 1995; Linnell et al., 1996; Bangs \& Shivik, 2001; Rigg, 2001; Fritts et al., 2003; Breitenmoser et al., 2005; SilleroZubiri et al., 2006). These include separating livestock and carnivores (e.g. predator-proof fencing, avoiding high risk areas/seasons, confining livestock at night or during bad weather), discouraging predators (e.g. electric fences, audio, visual and chemical repellents, conditioned taste aversion, proper carcass disposal, diversionary feeding, replacing vulnerable stock, adjusting calving/lambing seasons and location) and protecting livestock (e.g. guarding animals, harassing, shooting stock raiders with non-lethal projectiles, fitting protective collars, leaving horns on cattle). When preventive measures fail, the cost of damage is often compensated (Fourli, 1999). Managers may resort to selective removal of persistent stock raiders by lethal control (Treves \& NaughtonTreves, 2005) or translocation (Linnell et al., 1997). The effectiveness of these interventions in reducing conflicts has not always been adequately assessed.

In Slovakia a 30-year moratorium on hunting allowed the brown bear Ursus arctos to recover from 20-60 individuals in 1932 to $770-870$ (Rigg \& Adamec, 2007). Grey wolf Canis lupus and Eurasian lynx Lynx lynx numbers increased following growth of ungulate populations and partial legal protection to current estimates of 170-435 (Rigg, 2008) and c. 300 (Rigg, 2004), respectively. Current overlap of these species with sheep farming is $c$. $90 \%$ and predation on livestock is commonplace (Rigg, 2004). Compensation for damage by bears has been paid 
since 1962 and for damage by other species since 2003. In addition to regulated hunting, several non-lethal measures have been tried. Slovakia therefore represents an unusual opportunity for a case study of the long-term efficacy of different approaches to mitigation. Here, we analyse the scale of the conflict and evaluate strategies to improve coexistence, in particular the traditional use of livestockguarding dogs.

\section{Study area}

Livestock and large carnivores are largely confined to the Carpathian Mountains, which cover $59 \%$ of Slovakia's $49,035 \mathrm{~km}^{2}$. Typically, continuous woodland extends up to $1,400-1,600 \mathrm{~m}$ and consists primarily of spruce Picea abies in the north, with deciduous or mixed forests dominated by beech Fagus sylvatica at lower elevations. Mountain ranges are interspersed with lower-lying areas of higher human use and permanent settlement (Salvatori, 2004). Native red deer Cervus elaphus, roe deer Capreolus capreolus and wild boar Sus scrofa occur at medium-high densities. Commercial forestry, game management, gathering of forest fruits and recreation (hiking and skiing) are common.

Carnivore diet was studied in Tatranský, Nizke Tatry and Vel'ká Fatra National Parks and surrounding regions (Fig. 1), chosen for their abundant farms, carnivores and conflicts. Between the protected areas $\left(\leq 738 \mathrm{~km}^{2}\right)$ are scattered settlements and transport infrastructure in a mosaic of pastures, meadows, fields and woodland. Mean human population density in Liptovský Mikulás district in 2001-2005 was $55 \mathrm{~km}^{-2}$ (SOSR, 2008). Sheep are usually grazed in unfenced pastures attended by a shepherd and herding dog; one to five shepherds spend the night nearby in a caravan, cabin or farm building.

\section{Methods}

\section{Carnivore diet}

The proportion of livestock in carnivore diets was studied by faecal analysis. Faeces were collected $0-15 \mathrm{~km}$ from grazing areas in 2001-2004, during months when flocks were outdoors, and stored at $-18^{\circ} \mathrm{C}$. Investigation for dietary content followed standard procedures (Rigg \& Gorman, 2004, 2006). Hairs were identified using a reference collection and published keys and photographs (Dziurdzik, 1973; Teerink, 1991).

\section{Impact of predation}

Data on livestock were compiled from official publications (e.g. MPSR, 200o). Bear damage was assessed from compensation claims verified by inspection commissions and additional data in the literature (Rigg, 2004; Rigg \& Adamec, 2007). Equivalent records for other species were unavailable because damage was not usually compensated before 2003. Therefore, we estimated sheep losses to wolves, lynx and bears in 2001-2003 by extrapolating from reports at 164 flocks, evaluating reliability by comparison with records of verified bear damage.

To investigate relationships between predator numbers and damage we used official game statistics, which are compiled at Zvolen Forestry Research Institute based on questionnaires returned by all hunting ground users. We commissioned a summary of reported predator numbers by region $(n=36)$ for the years 2000-2002 (Rigg, 2004). These are the only nationwide data on large carnivore populations. Although they overestimate total population size because of multiple counting of the same individuals in two or more hunting grounds, they enable comparisons between regions and years. We considered a species to be present in a region if hunters reported it in $\geq 2$ of 3 years.

\section{Local conditions related to losses}

Damage records showed that most losses to carnivores were of upland sheep. In August-September 2003 we visited a stratified random sample of 164 flocks at 147 different farms in 20 of 25 administrative regions identified as having $\geq_{1}$ large carnivore species. These regions harboured $95-97 \%$ of bears, lynx and wolves in Slovakia (Rigg, 2004). An effort was made to include a representative variety of locations at different elevations and distances from roads and settlements. The flocks contained a total of 79,000 sheep, $26 \%$ of all those in regions with large carnivores (MPSR, 2000).

Trained field workers gathered data from farm personnel using a semi-structured interview protocol (Rigg, 2004). A mixture of open and fixed-response questions covered numbers of livestock, shepherds and dogs, husbandry practices, shepherds' experience, damage prevention methods, alleged predation and details of attacks. The response rate to the interview (but not every item) was $>95 \%$. After the 2003 grazing season $87 \%$ of farms were contacted by telephone or revisited to add reports of additional losses. To identify which factors best explained variation in losses, flocks were assigned to categories: no losses (no predation reported in 2001-2003), low-medium losses (1-9 head of livestock lost in 1 year) and high/repeated losses ( $\geq 10$ head of livestock lost in 1 year or predation in $\geq 2$ years).

In August-October 2005 we evaluated 77 flocks with 30,000 sheep using an expanded recording schedule. Field workers recorded distances to forest cover, village and paved road as well as several habitat variables.

\section{On-farm livestock-guarding dog trials}

The tradition of using livestock-guarding dogs was abandoned in Slovakia in the mid 2oth century, when large carnivores had become rare. Large sheepdogs are still kept 


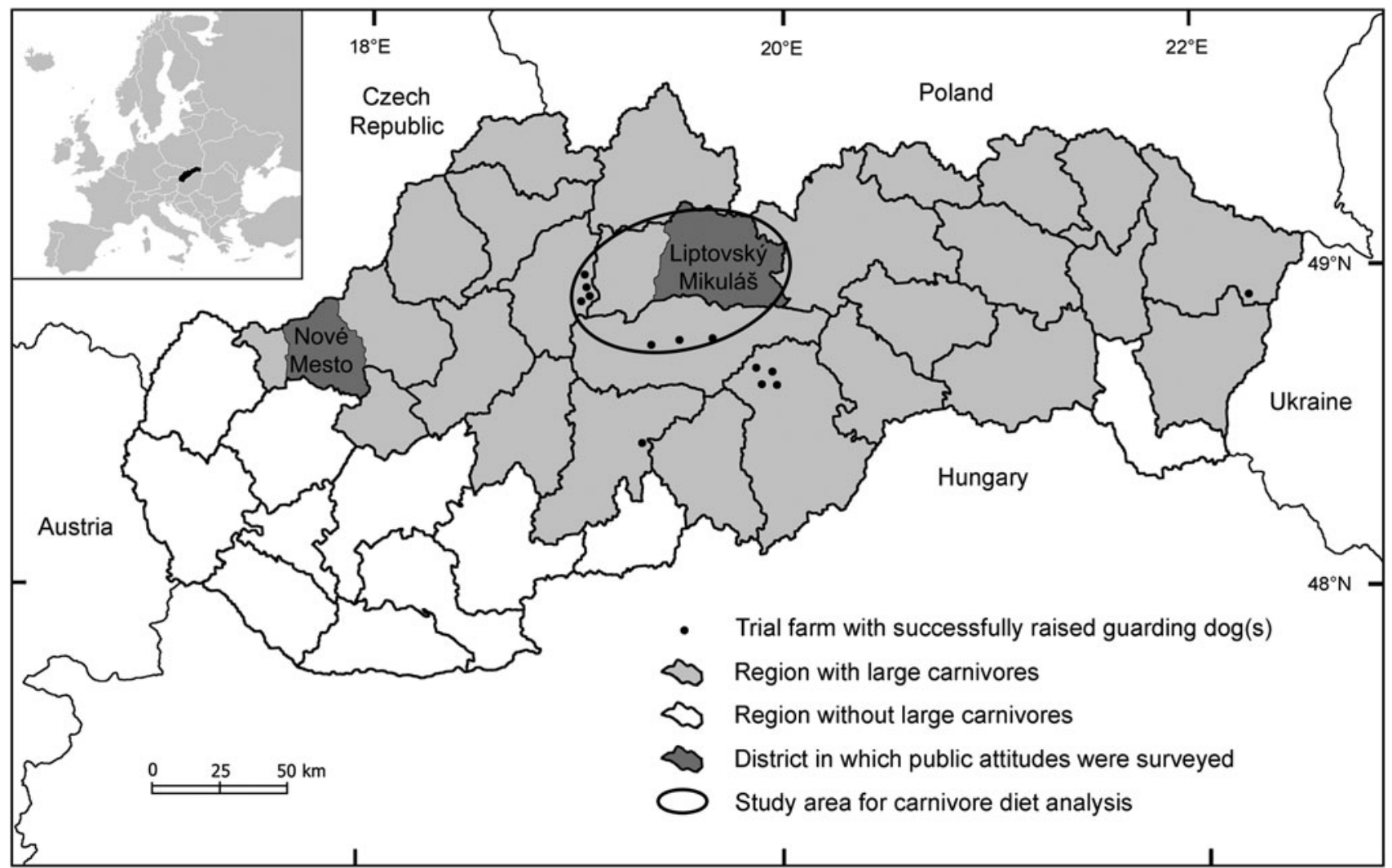

FIG. 1 Study areas and trial farms in relation to large carnivore distribution in Slovakia. The shaded area on the inset indicates the location of Slovakia in Europe.

at $>90 \%$ of farms but most are permanently chained near the sheepfold or farm buildings (Rigg, 2004). They may confer a benefit in alerting shepherds or dissuading less determined predators but cannot repel stock raiders.

To test the hypothesis that free-ranging livestockguarding dogs accompanying flocks would be more effective, guarding dogs were introduced to livestock operations following procedures developed in North America (Lorenz \& Coppinger, 1996; Dawydiak \& Sims, 2004). In 2000-2004 the Protection of Livestock and Conservation of Large Carnivores Project supplied farmers, free of charge, with a total of 68 pups of two different breeds: Slovenský čuvač ( 26 pedigree dogs and seven crossbreeds) and Caucasian shepherd $\operatorname{dog}$ ( 32 and three, respectively). Pups were bought from dog breeders or stockmen, dewormed, vaccinated against distemper, parvovirus and rabies, and placed at working farms opting into the project. In most cases high quality commercial dog food was provided. Age at first contact with sheep was $5-13$ weeks (median $=7$ ) depending on availability of suitable pups and farms. Participating stockmen were asked to keep them in specially constructed enclosures, or barns, with $\geq 5$ young sheep that were to be regularly exchanged for different individuals throughout the socialization period, minimizing pups' interactions with other dogs and humans. Subsequently, shepherds were encouraged to take young dogs out to pasture until eventually they could accompany flocks day and night. Regular telephone contact was maintained with livestock owners and shepherds and farms were visited at least once per month to check the health and progress of pups and address any problems.

Fourteen dogs were studied in detail using quantitative focal observation protocols to measure pups' behaviour and interactions with sheep (Rigg, 2004). Each was given three outcome ratings on a continuous 1-10 scale (Martin \& Bateson, 1993) for the extent to which (1) shepherds followed recommended guidelines, (2) the dog manifested preferred behavioural traits (Coppinger et al., 1983), and (3) the dog became integrated into the flock (bonded to sheep, free-ranging and regularly accompanied sheep to pasture). Ratings were converted into scores as follows: lower third of the range $=$ poor, middle third $=$ intermediate, and upper third $=$ good.

Reported losses for 2002 were compared at flocks with successfully integrated 1- to 2-year-old livestock-guarding dogs (trial) vs others in the same regions without such dogs (control). We did not use a before-and-after comparison (Marker et al., 2005) because we had previously observed substantial inter-annual variation in predation rates, irrespective of preventive measures.

\section{Attitudes}

A self-administered written questionnaire was given to 800 residents $>16$ years old, 157 school pupils aged $12-15$ years, 
121 woods-people (shepherds, farmers, hunters, foresters and mountain lodge staff), and 30 tourists in districts within the core (Liptovský Mikulás) and at the periphery (Nové Mesto nad Váhom) of large carnivore distribution, as well as 70 shepherds/farmers in other districts with carnivores. Attitudinal questions were measured on a 5-point Likert scale ranging from, for example, very negative to very positive (Wechselberger et al., 2005). The overall response rate (usable questionnaires only) was $>90 \%$. A mean attitude score was calculated from responses to 13 questions on attitudes towards wolves, bears and lynx. The interview protocol on farm conditions also included two questions relating to attitudes towards preventive measures (response rate: $25-65 \%$ ).

\section{Data analysis}

Data on farm conditions, reported losses and dog trials were analysed with non-parametric tests for statistical comparisons using Minitab v. 13.30 (Minitab, State College, USA). Individual dogs, rather than farms or litter averages, were treated as independent data points. Data from the questionnaire survey were analysed using either a $\chi^{2}$ test of association or an independent samples $t$-test (MannWhitney $U$ test and Kruskal-Wallis $H$ test) using SPSS $v$. 10.o (SPSS, Chicago, USA).

\section{Results}

\section{National vs local level of losses}

Bear damage to agriculture was inconsequential on a national scale: compensation in 1998-2006 totalled EUR $18,700-62,400$ per annum at constant prices whereas, in 2001, direct payments to subsidize livestock production amounted to EUR 38 million (MPSR, 2002). Sheep/goats accounted for $44 \%$ of compensation payments, apiaries $40 \%$ and cattle/horses $11 \%$. Total annual compensation payments have increased steadily in absolute values, correlated with hunters' estimates of bear numbers $(r=0.969$, $\mathrm{P}=0.007)$. However, the numbers of livestock killed and the value of economic damage at constant prices have remained steady or declined (Fig. 2).

Annual sheep losses were estimated at 1,625 to wolves, 290 to bears (compensation was paid for c. 200) and four to lynx. In 2004 reported losses averaged 3.1 sheep per flock to wolves and 0.7 to bears, representing 0.8 and $0.2 \%$ of sheep, respectively. Livestock was not a major component of carnivore diet. None of 373 bear faeces contained livestock remains. Cattle and sheep were each identified in one of 78 wolf faeces during spring-autumn.

Damage varied widely among farms. Almost half the shepherds interviewed in 2005 said they rarely or never had problems with predation, whereas $12 \%$ of flocks accounted

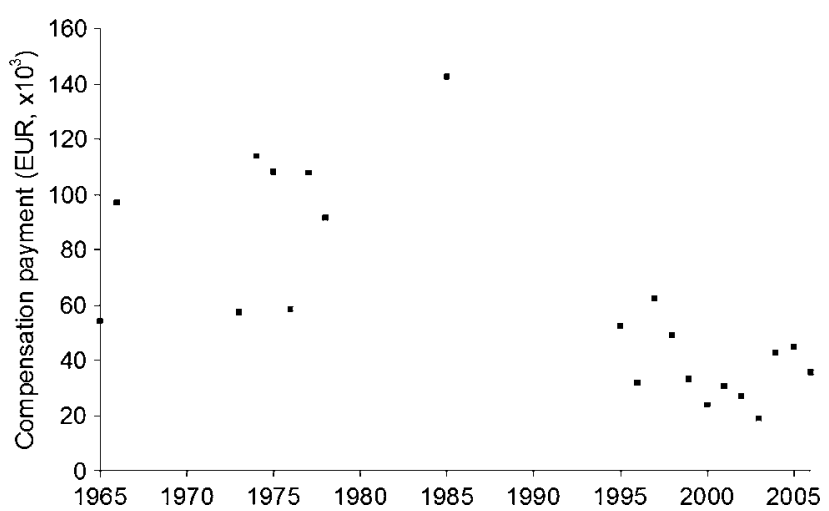

FIG. 2 Total annual compensation payments for damage attributed to bears during 1965-2006, adjusted to constant prices using annual inflation rates provided by the Statistics Office of the Slovak Republic and converted using the National Bank of Slovakia exchange rate of $1 \mathrm{EUR}=34.573$ SKK on 31 December 2006.

for $79-82 \%$ of all losses to bears and wolves in 2001-2003. The same flocks tended to be affected each year $\left(\chi^{2}=27.01\right.$, $\mathrm{df}=1, \mathrm{P}<0.001, \mathrm{n}=131)$ and by both species $\left(\chi^{2}=10.23\right.$, $\mathrm{df}=1, \mathrm{P}<0.001, \mathrm{n}=119)$. At a small number of flocks repeated attacks or occasional instances of surplus killing (in which predators, particularly wolves, killed more prey than necessary to sate their hunger; Kruuk, 1972), caused major losses ( $\leq 60$ sheep per attack). Less than $11 \%$ of flocks in any 1 year had total losses of $>10$ sheep but these hardhit flocks together accounted for $56-76 \%$ of all damage.

\section{Farm characteristics}

Flocks with high/repeated losses $(n=51)$ accounted for 83$96 \%$ of all reported losses each year. The most significant difference $\left(\chi^{2}=21.41, \mathrm{df}=1, \mathrm{P}<0.001\right)$ between flocks in this category and those with no losses was the method of night-time confinement. Whereas $57 \%$ of flocks with no losses $(n=61)$ were always or sometimes confined in a barn or farmyard, $86 \%$ of flocks with high/repeated losses were left in the pasture, either in a mobile sheepfold or loose. Eightysix percent of losses to bears were reported to occur at night vs $67-70 \%$ for wolves. Losses reported from 93 flocks kept in pastures at night averaged 3.6 sheep per flock compared to 0.4 for 47 flocks always or sometimes returned to a barn (Mann-Whitney $U$ test, $\mathrm{P}<0.001$ ). Losses dropped to zero when flocks were confined to barns in winter. We found no correlations between predation and flock size (range: 1002,000 sheep), numbers of dogs or shepherds' experience.

The most important habitat variables related to vegetation cover: none of seven sheep farms $>500 \mathrm{~m}$ from the forest edge had major losses, whereas all 13 flocks with high/ repeated losses were $<500 \mathrm{~m}$ from forest cover (Fisher's Exact Test, $\mathrm{P}=0.029, \mathrm{n}=36$ ). Wolves frequently attacked grazing flocks during daylight hours. Although we did not detect a significant difference within our sample $(P=0.127$, 
$n=36$ ), there seemed to be a trend for brushy pastures to be more susceptible to predation.

\section{Uptake and effectiveness of livestock-guarding dogs}

Of 34 pups placed at farms in 2000-2004, 17 were successfully integrated into flocks during their first full grazing season, five were partially integrated, 10 were separated from livestock by shepherds (three because of untrustworthiness or excessive roaming; seven without justification) and two died. Total known mortality by 2 years of age was $\geq 7$ of 68 dogs due to the following causes: shot by hunters $(n=2)$, hit by vehicles $(2)$, poisoned (1), bad food (1), infection (1). An additional three dogs disappeared. Of 14 dogs studied in detail, 12 showed good or acceptable patterns of behaviour, retaining key traits of trustworthiness, attentiveness and protectiveness.

The presence of livestock-guarding dogs was associated with lower levels of predation and an absence of surplus killing. The mean loss reported at 13 trial flocks in 2002 was 1.1 sheep compared to 3.3 for 45 control flocks in the same regions. Five of the control flocks lost 10-35 sheep/goats, whereas the maximum loss at trial flocks, from which shepherds saw dogs chasing away predators, was five. An overall difference in the median level of losses between trial and control flocks was not detected. However, when selecting trial sites, flocks that had previously suffered from predation were preferred, so control flocks tended to be less prone to attacks regardless of how they were managed. If only flocks that suffered predation are considered in both groups, damage was significantly lower (Mann-Whitney $U$ test, $\mathrm{P}=0.015)$ at trial flocks, where the median loss was 1.5 sheep (inter-quartile range: $1-4, n=6$ ) compared with 5.0 at control flocks (inter-quartile range: $3-10, n=16$ ).

\section{Other preventive measures}

Electric fences were used at 28 of 152 flocks (18\%) surveyed in 2003. Typically, they were of a type designed to contain livestock rather than exclude predators. No significant difference was found in the number of sheep predated at flocks with vs without such fences.

Of 136 farm personnel who answered a question on prevention 34 (25\%) said they used other methods. Guarding/patrolling was mentioned 17 times, returning the flock to the farmyard or secure fencing nine times and aversive devices nine times. Shepherds sometimes succeeded in chasing predators away whereas, in other cases, unwary carnivores killed sheep despite their interventions. Some attacks were not discovered until it was too late. Firecrackers, lamps and other simple aversive devices were said to be helpful but, if encountered repeatedly, predators habituated to them.

At least 21 'problem' bears have been live-trapped and relocated but, typically, these were human-habituated food conditioned individuals (Rigg \& Baleková, 2003). Monitoring has generally been insufficient to assess outcomes.

Permits were issued annually for the shooting of $\leq 10 \%$ of estimated bear numbers. In 2000-2006, trophy hunters shot on average 24 bears per annum, $35 \%$ of the total permitted. According to official guidelines, hunting is targeted at areas where conflicts with human interests occurred in the previous year, the assumption being that population control can limit damage to socially acceptable levels. However, the regional allocation of the 2002 hunting quota correlated more strongly with bear distribution than compensation payments in 2001 (Fig. 3). Sheep numbers $\left(r_{\mathrm{s}}=0.733\right.$, $\mathrm{P}=0.001)$ explained more of the inter-regional variation in losses than did bear numbers $\left(r_{s}=0.697, P=0.001\right)$. In addition to the planned harvest three problem bears were removed, on average, annually, half of them following damage to livestock or beehives. During our study there were no restrictions on the number of wolves that could be shot during the open season (1 November to 15 January). The average annual harvest in 1997-2005 was 88 . The regional distribution of wolves derived from hunters' reports explained $22-41 \%$ of variation in number and percentage of sheep reported lost to wolves and proportion of flocks allegedly affected. Hunting lynx has been illegal since 1999.

\section{Attitudes to predator management}

A large majority of survey respondents $(83 \%, n=1,178)$ agreed that, 'Bears, wolves and lynx belong in the wild in Slovakia'. Most did not agree that they 'kill a lot of livestock'. However, those who had experienced damage held significantly more negative attitudes. Shepherds had the most negative attitudes of nine occupational groups questioned (Fig. 4).

Most respondents $(61 \%, \mathrm{n}=1,076)$ agreed that livestock owners should receive compensation for losses; only $30 \%$ knew it was already available. Almost half thought payment should be conditional on use of preventive measures, as required by law since 2003. Woods-people more often agreed $(61 \%)$ with this than other target groups $\left(\chi^{2}=39.52\right.$, $\mathrm{P}<0.001)$. Most shepherds interviewed $(63 \%, \mathrm{n}=32)$ asserted that they were interested in improving flock protection measures. Nevertheless, when asked, 'What could help prevent attacks by predators?', only $16 \%$ of them mentioned a non-lethal method. Most $(58 \%, \mathrm{n}=19)$ cited shooting predators as a way to prevent attacks. Measures most often reported to have been very effective in reducing predation were enclosing the flock in a barn/ farmyard at night or when it rains, using livestock-guarding dogs, increasing vigilance and chasing away predators.

Survey respondents equally agreed $(38 \%)$ as disagreed $(35 \%)$ that carnivores should be eliminated from areas where they kill livestock. Only $30 \%$ of woods-people were in favour of this, fewer than any other target group except 

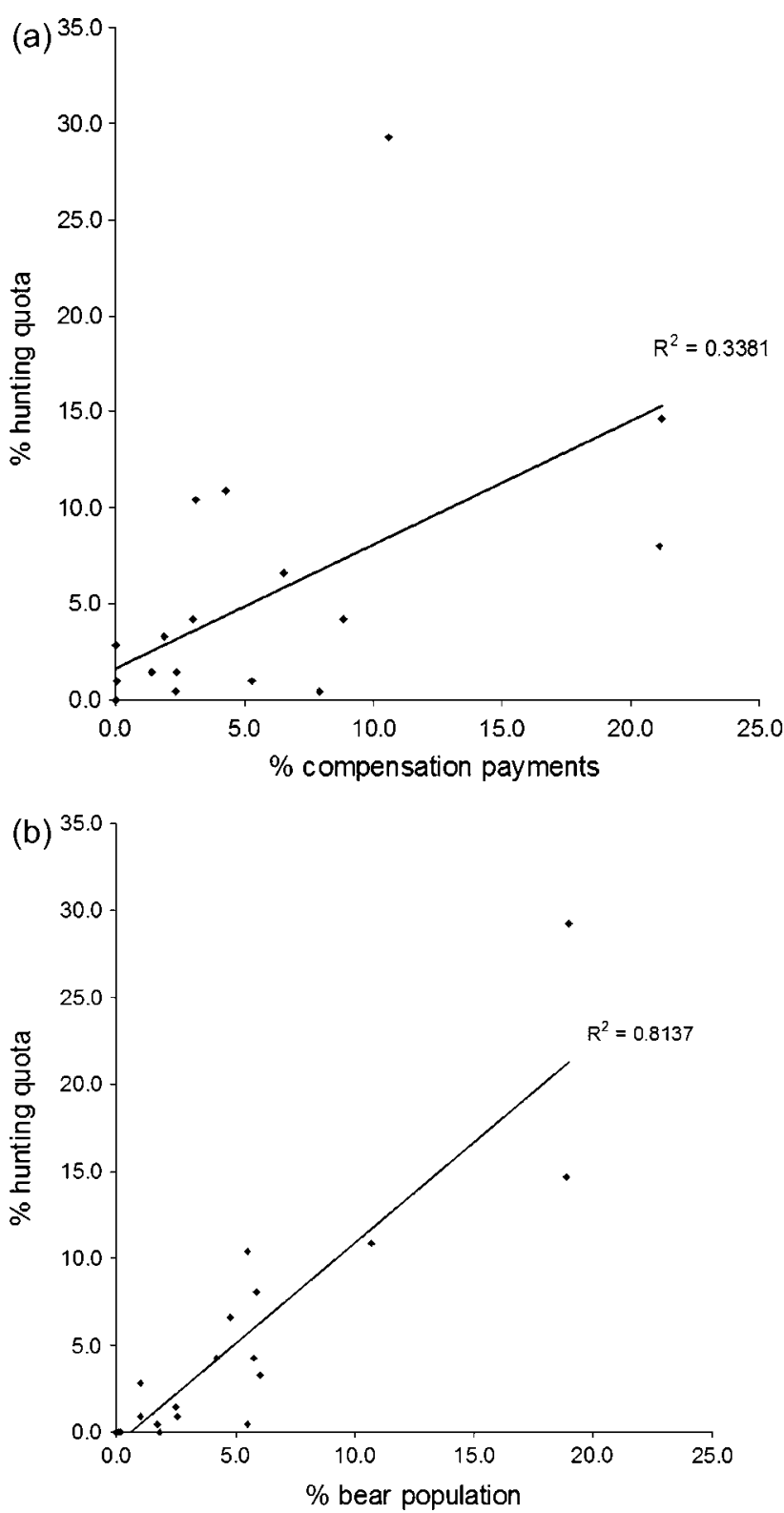

Fig. 3 Relation of regional distribution of bear hunting permits allocated in 2002 to (a) distribution of compensation payments in 2001 and (b) distribution of bear numbers as estimated by hunting ground users for 2001.

tourists $\left(14 \% ; \chi^{2}=52.80, \mathrm{P}<0.001\right)$. This seems paradoxical, as woods-people most often thought there were too many bears and that carnivores caused a lot of damage. Threequarters of respondents $(78 \%$ of those in the core area and $70 \%$ of woods-people) agreed that hunting of large carnivores should be strictly regulated.

\section{Discussion}

Set against the general level of prosperity in Europe, carnivore-livestock conflict is more a social and psychological problem than a financial one (Fourli, 1999). Although some individuals in poor rural communities suffer signifi- cant impacts (Mertens \& Promberger, 2001), only a small proportion of livestock operations are seriously affected (Kaczensky, 1996). Perception of economic loss may differ among individuals and social groups (Wechselberger et al., 2005) or in relation to the historical presence or absence of carnivores (Ricci et al., 2006). Conflict mitigation is therefore not only a question of reducing actual damage but also of increasing tolerance (Sillero-Zubiri et al., 2006).

In Slovakia a belief that there are too many bears has become entrenched in recent years even though the real cost of economic damage has not increased. Our results reaffirm that local conditions, not predator numbers, play a key role in determining the extent of losses (Kaczensky, 1996). Factors associated with increased risk of predation include landscape features (Treves et al., 2004; Jedrzejewski et al., 2005), distance to forest cover (Azevedo \& Murray, 2007), reduced availability of wild prey (Sidorovich et al., 2003) or, conversely, high densities of wild ungulates in pastures (Stahl et al., 2001; Treves et al., 2004), calving in forested or brushy pastures (Paul, 2000), lack of human attendance, guard animals or other preventive measures (Kaczensky, 1996) and, possibly, improper disposal of livestock carcasses (Mech et al., 2000). Some variables may be of a temporary nature; e.g. bears cause more damage during, or following, years of mast/berry crop failure (Ryan et al., 2007) and wolves predate more on livestock following milder winters (Mech et al., 1988). Damage hot spots may persist over time or reappear when predators recolonize the area (Stahl et al., 2002).

A combination of preventive measures, compensation for damage and elimination of problem individuals has been described as the most rational and effective approach in support of wolf conservation (Boitani, 2003). Each of these elements has been implemented in Slovakia to varying degrees but with greater emphasis placed on carnivore population control. The current system of permitting a largely untargeted harvest up to 1.5 years after damage occurred seems unlikely to be the most effective way to avert further attacks, although it may improve public acceptance of carnivores by empowering those affected (Treves \& Naughton-Treves, 2005). As not all individuals in carnivore populations are equally involved in conflicts (Jedrzejewski et al., 2003) selective removal of problem animals is more likely to reduce losses but can be difficult to achieve (Linnell et al., 1999) and, if circumstances remain otherwise unchanged, effects may be short term because of recolonization by conspecifics (Treves \& Naughton-Treves, 2005). Other measures are therefore required.

Since its introduction in 1962 compensation for bear damage has been conditional on an inspection commission absolving the owner or guardian of blame. Preconditions for payment from 2003 specifically mention use of prevention (enclosures, electric fences, guardians and 


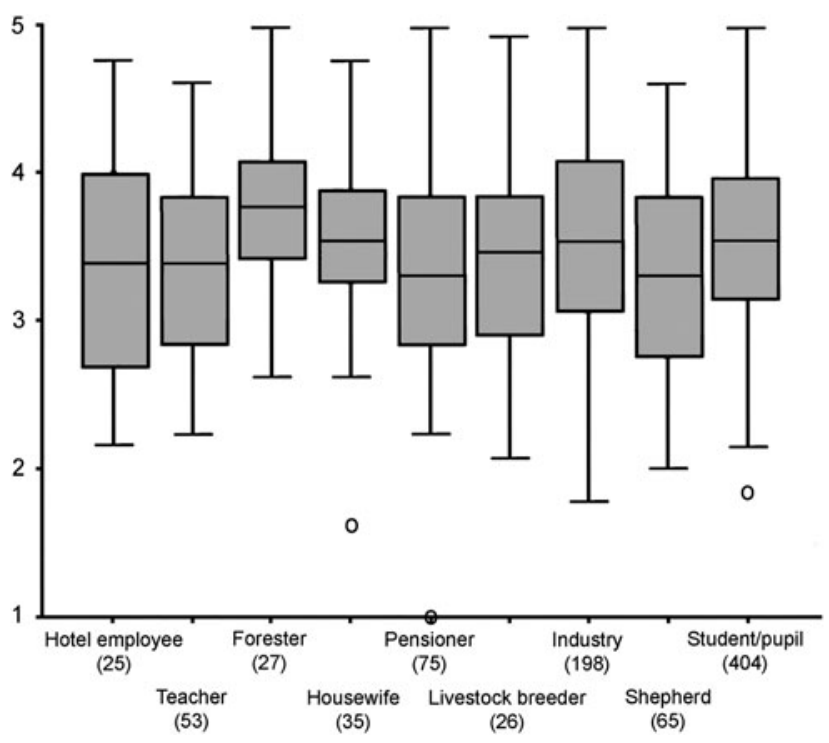

FIG. 4 Box and whisker plots of attitude to large carnivores according to occupation, with sample size in parentheses $(1=$ strongly negative attitude, $3=$ neutral and $5=$ strongly positive).

shepherd dogs). Nevertheless, ineffective methods (chained dogs and inadequate electric fencing) prevail and shepherds have the most negative attitudes to carnivores despite the availability of compensation.

Establishment of a team trained to implement mitigation measures could improve their efficacy and address people's grievances. The compensation scheme could be improved by streamlining bureaucratic procedures to reimburse afflicted parties promptly. Payments could be made proactively for tolerating carnivore presence (Schwerdtner \& Gruber, 2007). Other possibilities include subsidized insurance cover, providing replacement animals or compensating lost production, inconvenience and distress as well as the market value of depredated stock. For a compensation scheme to foster tolerance, people must know it exists. This was not usually the case during our study, and thus awareness needs to be raised.

Damage per carnivore is lower in Slovakia than some regions of Europe where they have recovered in smaller numbers; e.g. in Norway, the Alps and the Pyrenees (Kaczensky, 1996). This could be because of the presence of shepherds (possibly explaining the absence of lynx predation), use of preventive measures and relative availability of alternative food. The substantial influence of local conditions on predation levels implies that there is scope for improving prevention. Further research on predictors of damage could help identify farms predisposed to predation, where the financial cost of prevention could be recouped by a concomitant reduction in compensation payments.

As most predation occurs at night the method of confinement is important. Livestock is more vulnerable in simple sheepfolds or loose in the pasture than in a barn or securely-fenced farmyard. However, in Slovakia wolves also attack sheep during daylight hours. Pastures are usually unfenced and interspersed with woodland. Securing the whole grazing area with predator-proof fencing is unfeasible for most farms, so livestock-guarding dogs seem to be the best option for adequate flock protection where wolves are present.

Surplus killing has a major impact on individual farms and accounts for a large percentage of all losses, so its prevention has substantial benefits. Our results show that, although they did not eliminate losses, even young livestock-guarding dogs reduced predation and prevented surplus killing by actively repelling predators, as reported from Romania (Mertens \& Promberger, 2001).

In trials, the success or otherwise of raising livestockguarding dogs depended more on the attitude and diligence of shepherds than on differences between dogs in their behavioural conformation or genotype. The main obstacles to uptake were reluctance of shepherds to take on extra work, hostility of hunters concerned that free-ranging dogs might harass game (this resulted in the shooting of at least two of the dogs) and interactions between dogs and farm visitors. Likewise, the shortcoming of electric fencing in Slovakia was because of failings in its design or installation. Electric fencing can be highly effective at preventing damage if correctly implemented (Levin, 2002; Mertens et al., 2002).

To conclude, this case study illustrates that damage levels need not be excessive despite high predator densities in human-dominated European landscapes. Conflicts tend to be unevenly distributed, with a minority of livestock operations suffering high and repeated losses. Much of the variation is explained by local conditions, including husbandry practices and, in particular, preventive measures. Livestock-guarding dogs are one of the best ways to prevent substantial losses and are particularly appropriate where wolves are present in proximity to unfenced pastures.

The data presented in this article date from the period up to 2006. Since then the dogs have continued to work effectively and we have seen farmers and shepherds at 15 other farms raise free-ranging livestock-guarding dogs after witnessing them in use at trial farms. Our results have been presented to decision makers through presentations, publications and lobbying. Nevertheless, the attention of the Slovak authorities, farming and hunting communities, the media and general public has so far remained focused on considerations of predator population size and lethal control.

\section{Acknowledgements}

Several Slovak Wildlife Society projects provided data for this study: the Protection of Livestock and Conservation of Large Carnivores Project funded principally by the Born Free Foundation, The BEARS Project supported by WWF Denmark c/o the Danube-Carpathian Programme Office, 
and the Slovakia Wolf Census Project funded by the Wolves and Humans Foundation. Additional support was provided by the British Trust for Conservation Volunteers, the University of Aberdeen and private donors. For access to official records we thank M. Adamec at the State Nature Conservancy, Banská Bystrica and P. Kaštier of Zvolen Forestry Research Institute. Work on this article was kindly supported by The European Nature Trust and Oxford University's WildCRU. We thank P. Johnson for statistical advice and anonymous reviewers for their helpful comments.

\section{References}

Azevedo, F.C.C. \& Murray, D.L. (2007) Evaluation of potential factors predisposing livestock to predation by jaguars. Journal of Wildlife Management, 71, 2379-2386.

Bangs, E. \& Shivik, J. (2001) Managing wolf conflict with livestock in the north-western United States. Carnivore Damage Prevention News, 3, 2-5.

Boitani, L. (2003) Wolf conservation and recovery. In Wolves: Behavior, Ecology and Conservation (eds D.L. Mech \& L. Boitani), pp. 317-340. The University of Chicago Press, Chicago, USA.

Breitenmoser, U. (1998) Large predators in the Alps: the fall and rise of man's competitors. Biological Conservation, 83, 279-289.

Breitenmoser, U., Angst, C., Landry, J.-M., BreitenmoserWürsten, C., Linnell, J.D.C. \& Weber, J.-M. (2005) Nonlethal techniques for reducing depredation. In People and Wildlife: Conflict or Coexistence? (eds R. Woodroffe, S. Thirgood \& A. Rabinowitz), pp. 49-71. Cambridge University Press, Cambridge, UK.

Cluff, H.D. \& Murray, D.L. (1995) Review of wolf control methods in North America. In Ecology and Conservation of Wolves in a Changing World (eds L.N. Carbyn, S.H. Fritts \& D.R. Seip), pp. 491-504. Proceedings of the Second North American Symposium on Wolves, Edmonton, Alberta, Canada.

Coppinger, R., Lorenz, J., Glendinning, J. \& Pinardi, P. (1983) Attentiveness of guarding dogs for reducing predation on domestic sheep. Journal of Range Management, 36, 275-279.

Dawydiak, O. \& Sims, D.E. (2004) Livestock Protection Dogs: Selection, Care and Training. 2nd edition. Alpine, Loveland, USA.

Dziurdzik, B. (1973) Key to the identification of hairs of mammals from Poland. Acta Zoologica Cracoviensia, Tom 18, 73-113.

Fourli, M. (1999) Compensation for Damage Caused by Bears and Wolves in the European Union. Office for Official Publications of the European Communities, Luxembourg.

Fritts, S.H., Stephenson, R.O., Hayes, R.D. \& Boitani, L. (2003) Wolves and humans. In Wolves: Behavior, Ecology and Conservation (eds D.L. Mech \& L. Boitani), pp. 289-316. The University of Chicago Press, Chicago, USA.

Jedrzejewski, W., Niedzia 1 Kowska, M., Myslajek, R., Nowak, S. \& Jedrzejewski, B. (2005) Habitat selection by wolves Canis lupus in the uplands and mountains of southern Poland. Acta Theriologica, 50, 417-428.

Jedrzejewski, W., Nowak, S., Jedrzejewski, B., Myslajek, R., Rogala, M. \& Schmidt, K. (2003) Factors affecting wolf distribution, numbers and livestock depredation in Poland. In World Wolf Congress 2003 Bridging Science and Community. Book of Abstracts. Banff, Canada.

KaCzensky, P. (1996) Large Carnivore-Livestock Conflicts in Europe. Unpublished Report to Wildbiologische Gesellschaft München e.V., Linderhof, Germany.
KRUUK, H. (1972) Surplus killing by carnivores. Journal of Zoology, $166,133-244$.

Levin, M. (2002) How to prevent damage from large predators with electric fences. Carnivore Damage Prevention News, 5, 5-8.

Linnell, J.D.C., Aanes, R., Swenson, J.E., Odden, J. \& Smith, M.E. (1997) Translocation of carnivores as a method for managing problem animals: a review. Biodiversity and Conservation, 6, 12451257 .

Linnell, J.D.C., Odden, J., Smith, M.E., Aanes, R. \& Swenson, J. (1999) Large carnivores that kill livestock: do "problem individuals" really exist? Wildlife Society Bulletin, 27, 698-705.

Linnell, J.D.C., Smith, M.E., Odden, J., KaCzensky, P. \& Swenson, J. (1996) Carnivores and Sheep Farming in Norway. 4. Strategies for the Reduction of Carnivore-Livestock Conflicts: A Review. Norwegian Institute for Nature Research Oppdragsmelding 443, Trondheim, Norway.

Linnell, J.D.C., Swenson, J.E. \& Andersen, R. (2001) Predators and people: conservation of large carnivores is possible at high human densities if management policy is favourable. Animal Conservation, 4, 345-349.

Lorenz, J.R. \& Coppinger, L. (1996) Raising and Training a Livestock-Guarding Dog. Extension Circular 1238. Oregon State University Extension Service, Corvallis, USA.

Marker, L.L., Dickman, A.J. \& Macdonald, D.W. (2005) Perceived effectiveness of livestock-guarding dogs placed on Namibian farms. Rangeland Ecology and Management, 58, 329336.

Martin, P. \& Bateson, P. (1993) Measuring Behaviour: An Introductory Guide. 2nd ed. Cambridge University Press, Cambridge, UK.

Mech, L.D. (1996) A new era for carnivore conservation. Wildlife Society Bulletin, 24, 397-401.

Mech, L.D., Fritts, S.H. \& Paul, W.J. (1988) Relationship between winter severity and wolf depredations on domestic animals in Minnesota. Wildlife Society Bulletin, 16, 269-272.

Mech, L.D., Harper, E.K., Meier, T.J. \& Paul, W.J. (2000) Assessing factors that may predispose Minnesota farms to wolf depredation on cattle. Wildlife Society Bulletin, 28, 623-629.

Mertens, A. \& Promberger, C. (2001) Economic aspects of large carnivore-livestock conflicts in Romania. Ursus, 12, 173-180.

Mertens, A., Promberger, C. \& Gheorge, P. (2002) Testing and implementing the use of electric fences for night corrals in Romania. Carnivore Damage Prevention News, 5, 2-5.

MPSR (Ministry of Agriculture of the Slovak Republic) (2000) Koncepcia rozvoja chovu oviec $v$ SR do roku 2005. Report to Ministry of Agriculture of the Slovak Republic, Bratislava, Slovakia. Http://www.mpsr.sk/index.php [accessed 30 September 2004].

MPSR (Ministry of Agriculture of the Slovak Republic) (2002) The Green Report. Ministry of Agriculture of the Slovak Republic, Bratislava, Slovakia.

PAUL, W.J. (2000) Trends and management of wolf-livestock conflicts in Minnesota. In Beyond 2000 Realities of Global Wolf Restoration. Conference Abstracts. International Wolf Center, Ely, USA.

Ricci, S., Salvatori, V. Mertens, A. \& Teofili, C. (2006) Public opinions and damage prevention in Central Italy. In Management of Conflicts between Wildlife and Human Resource Use. Conference Abstracts. Leipzig, Germany. Http://www.peopleandwildlife.org.uk/board/FRAPconf-abstracts.pdf [accessed 9 July 2008].

RIGG, R. (2001) Livestock Guarding Dogs: Their Current Use World Wide. IUCN/SSC Canid Specialist Group Occasional Paper No 1. Canid Specialist Group, Oxford. Http://www.canids.org/ occasionalpapers [accessed 9 July 2008]. 
Rigg, R. (2004) The Extent of Predation on Livestock by Large Carnivores in Slovakia and Mitigating Carnivore-Human Conflict Using Livestock Guarding Dogs. MSc thesis, University of Aberdeen, Aberdeen, UK.

RIGG, R. (2008) Abundance, hunting and protection of the wolf (Canis lupus) in the Slovak Carpathians-too much or not enough? In Výskum a ochrana cicavcov na Slovensku VIII (eds M. Adamec, P. Urban \& M. Adamcová), pp. 200-213. Conference Proceedings. State Nature Conservancy of the Slovak Republic, Banská Bystrica, Slovakia.

Rigg, R. \& Adamec, M. (2007) Status, Ecology and Management of the Brown Bear (Ursus arctos) in Slovakia. Unpublished Report by the Slovak Wildlife Society, Liptovský Hrádok, Slovakia.

Rigg, R. \& BalekovÁ, K. (eds) (2003) The Integrated Solution to the Problem of Nuisance Bears (Ursus arctos). Sloboda zvierat, Bratislava, Slovakia.

Rigg, R. \& Gorman, M. (2004) Spring-autumn diet of wolves (Canis lupus) in Slovakia and a review of wolf prey selection. Oecologia Montana, 13, 30-41.

RIGG, R. \& Gorman, M. (2006) Diet of brown bears (Ursus arctos): new results from the Tatras region and a comparison of research methods. In Výskum a ochrana cicavcov na Slovensku VII (eds M. Adamec \& P. Urban), pp. 61-79. Conference Proceedings. State Nature Conservancy of the Slovak Republic, Banská Bystrica, Slovakia.

Ryan, C.W., Pack, J.C., Igo, W.K. \& Billings, A. (2007) Influence of mast production on black bear non-hunting mortalities in West Virginia. Ursus, 18, 46-53.

Salvatori, V. (2004) Mapping Conservation Areas for Large Carnivores in the Carpathian Mountains. $\mathrm{PhD}$ thesis, University of Southampton, Southampton, UK.

Schwerdtner, K. \& Gruber, B. (2007) A conceptual framework for damage compensation schemes. Biological Conservation, 134, 354-360.

Sidorovich, V.E., Tikhomirova, L.L.. \& Jedrzejewska, B. (2003) Wolf Canis lupus numbers, diet and damage to livestock in relation to hunting and ungulate abundance in northeastern Belarus during 1990-2000. Wildlife Biology, 9, 103-111.

Sillero-Zubiri, C. \& Laurenson, M.K. (2001) Interactions between carnivores and local communities: conflict or co-existence? In Carnivore Conservation (eds J.L. Gittleman, S.M. Funk, D.W. Macdonald \& R.K. Wayne), pp. 282-312. Cambridge University Press, Cambridge, UK.

Sillero-Zubiri, C., Sukumar, R. \& Treves, A. (2006) Living with wildlife: the roots of conflict and the solutions. In: Key Topics in Conservation Biology (eds D.W. Macdonald \& K. Service), pp. 253-270. Blackwell Publishing, Oxford, UK.
SOSR (Statistical Office of the Slovak Republic) (2008) Slovstat Online. Statistical Office of the Slovak Republic, Bratislava, Slovakia. Http://www.statistics.sk [accessed 9 July 2008].

Stahl, P., Vandel, J.M., Herrenschmidt, V. \& Migot, P. (2001) Predation on livestock by an expanding reintroduced lynx population: long-term trend and spatial variability. Journal of Applied Ecology, 38, 674-687.

Stahl, P., Vandel, J.M., Ruette, S., Coat, L., Coat, Y. \& B ALESTRA, L. (2002) Factors affecting lynx predation on sheep in the French Jura. Journal of Applied Ecology, 39, 204-216.

Teerink, B.J. (1991) Hair of West-European Mammals. Atlas and Identification Key. Cambridge University Press, Cambridge, UK.

Treves, A. \& Naughton-Treves, L. (2005) Evaluating lethal control in the management of human-wildlife conflict. In People and Wildlife: Conflict or Coexistence? (eds R. Woodroffe, S. Thirgood \& A. Rabinowitz), pp. 86-106. Cambridge University Press, Cambridge, UK

Treves, A., Naughton-Treves, L., Harper, E.K., Mladenoff, D.J., Rose, R.A., Sickley, T.A. \& Wydeven, A.P. (2004) Predicting carnivore-human conflict: a spatial model derived from 25 years of data on wolf predation on livestock. Conservation Biology, 18, 113-125.

Wechselberger, M., Rigg, R. \& Beťková, S. (2005) An Investigation of Public Opinion about the Three Species of Large Carnivore in Slovakia: Brown Bear (Ursus arctos), Wolf (Canis lupus) and Lynx (Lynx lynx). Unpublished Report to Slovak Wildlife Society, Liptovský Hrádok, Slovakia.

Woodroffe, R., Thirgood, S. \& Rabinowitz, A. (2005) People and Wildlife: Conflict or Coexistence? Cambridge University Press, Cambridge, UK.

\section{Biographical sketches}

RовIN Rigg has been endeavouring to mitigate carnivore-human conflicts in Slovakia since 1998. After first working with livestockguarding dogs he established and leads The BEARS Project (http:// www.medvede.sk). SLAvomír FinDo has been researching wolves and their prey in Slovakia since the 1990s. MARIA WECHSELBERGER has carried out human-dimensions research on large carnivores in Slovakia, Canada and her native Austria. Martyn L. Gorman's main research interest is the ecology and conservation biology of wild mammals. Claudio Sillero-Zubiri is Chair of the IUCN/Species Survival Commission Canid Specialist Group. His interests include the conservation of threatened species and human-wildlife conflict. DAVID W. MACDONALD is the founder and Director of WildCRU. 